\title{
ANÁLISE MULTITEMPORAL DO DESMATAMENTO OCORRIDO ENTRE 2006 E 2017 NO SUDESTE DO PARÁ
}

\author{
MULTITEMPORAL ANALYSIS OF DEFORESTATION THAT OCCURRED BETWEEN 2006 AND 2017 IN \\ SOUTHEAST PARÁ.
}

Antônio Pereira Júniora , Lucimar Costa Pereira ${ }^{b}$, Layla Bianca Almeida Diasc, Paulo da Silva Garciac

aUniversidade do Estado do Pará - Campus VI, Paragominas; bUniversidade Federal do Pará, 'Universidade do Estado do Pará, Campus VIII, Marabá.

antonio.junior@uepa.br, lu.costa0708@gmail.com, dlaylabianca@gmail.com, eng.ambpaulogarcia@gmail.com

Submissão: 04 de agosto de 2020 Aceitação: 24 de novembro de 2020

\section{Resumo}

O objetivo desta pesquisa foi realizar uma análise evolutiva sobre o desflorestamento ocorrido na sub-bacia hidrográfica do rio Itacaiúnas, região sudeste do Pará, no período de 2006 a 2017, em quatro intervalos trienais (2006-2008, 2009-2011, 2012-2014, 2015-2017). O método empregado foi o dedutivo, com abrangência quantitativa e qualitativa, de natureza aplicada. Os dados para elaboração dos mapas temáticos foram obtidos na base de dados geográficos do Instituto Nacional de Pesquisas Espaciais (INPE), do Sistema de Detecção de Desflorestamento em Tempo Real (DETER), do programa de Monitoramento da Floresta Amazônica Brasileira por Satélite (PRODES), para, em seguida processar e tratar as informações coletadas com uso da ferramenta de densidade de Kernel, a partir do "software" QGis versão 3.4 Itr. Já os dados secundários foram obtidos em bases de dados de acesso livre, como Scientific Eletronic Library Online (SciELO), Coordenação de Aperfeiçoamento do Pessoal de Ensino Superior (CAPES), Web Science e Google Scholar, com recorte temporal situado entre 2011 e 2020, exceto as literaturas e leis. Os dados obtidos e analisados indicaram que o período de 2006 a 2008 concentrou o maior número de registro de áreas desflorestadas, que o menor ocorreu entre 2012 e 2014 e que os municípios de Marabá, São Geraldo, Eldorado dos Carajás, Piçarra, Água Azul do Norte e Canaã dos Carajás foram aqueles que registraram a maior quantidade de pontos quanto aos desflorestamentos. Com isso, foi verificado que o controle por georreferenciamento e a presença dos órgãos de fiscalização são úteis na avaliação do desflorestamento.

Palavras-chave: desflorestamento; intensidade de Kernel; sub-bacia do rio Itacaiúnas.

\section{Abstract}

The objective of this research was to conduct an analysis of the evolution of deforestation in the Sub-basin of the Itacaiúnas River, located in the southeastern region of Pará, from 2006 to 2017, in four three-year intervals (2006-2008, 2009-2011, 2012-2014, 2015-2017). The method used was the deductive one, with quantitative and qualitative scope, of nature applied. The data for the elaboration of thematic maps were obtained from the geographic database of the National Institute for Space Research (INPE), the Real-Time Deforestation Detection System (DETER), the Brazilian Amazon Forest Satellite Monitoring Program (PRODES) and then processed and treated the data acquired using the Kernel Density Tool from the software QGis version 3. Four Itr. The secondary ones were obtained in open-access databases such as Scientific Electronic Library Online (SciELO), Higher Education Thought Improvement Coordination (CAPES), Web Science, and Google Scholars with time clipping located between 2011 and 2020, except for literature and laws. The data obtained and analyzed indicated that the period 2006-2008 concentrated the most significant number of deforested areas, and the smallest occurred between 2012 and 2014. They also noted that the municipalities of Marabá, São Geraldo, Eldorado dos Carajás, Piçarra, Água Azul do Norte and Canaã dos Carajás were those that registered the highest number of deforestation points. With this, it was verified that the control by georeferencing and the presence of the inspection agencies are useful in the deforestation. 
Keywords: deforestation; kernel intensity; Sub-basin of the Itacaiúnas River.

\section{INTRODUÇÃO E FUNDAMENTAÇÃO TEÓRICA}

O ecossistema amazônico tem sofrido redução de sua qualidade ambiental com 0 aumento anual da degradação florestal. Os órgãos de monitoramento, nas análises anuais que efetuaram, identificaram que o desmatamento na Amazônia Legal, de acordo com o Instituto do Homem e do Meio Ambiente da Amazônia (IMAZON), de 2018 a 2019, por meio do Sistema de Alerta de Desmatamento (SAD), teve um aumento de 54\% (IMAZON, 2019). O objetivo do desmatamento é viabilizar um progresso econômico a partir da implementação de atividades urbanas, agrícolas, exploração e geração de energia (ARVOR et al., 2017; CHEN et al., 2015).

Com o objetivo de reduzir, controlar e prevenir o desmatamento, não só na Amazônia Legal, mas em todo o Brasil, foi tomada uma série de medidas, tais como: Avaliação de Impacto Ambiental (AIA); Resolução do Conselho Nacional de Meio Ambiente (CONAMA), 001/86; Constituição Federal do Brasil (1988), Cap. VI, art. 225; Projeto de Monitoramento do Desmatamento na Amazônia Legal (PRODES) lançado em 1988; criação de Unidades de Conservação (UC's), o que ocorreu em $2000 \mathrm{com}$ a promulgação da Lei n. 9985 (BRASIL, 2000); e o Plano de Ação para Prevenção e Controle do Desmatamento na Amazônia Legal (PPCDAm), lançado em 2004 (CASTELO, 2015).

Outros mecanismos foram adotados como, por exemplo, o Plano Estratégico Nacional de Áreas Protegidas, Decreto n. 5 758/06 (MMA, 2011). Essas medidas tinham como objetivo principal, alcançar o "desmatamento zero" (MOUTINHO; GUERRA; AZEVEDO-RAMOS, 2016), sem diminuir a evolução econômica nessa região, como, por exemplo, extinguir o desmate voltado à produção agropecuária e promover a instalação desta em áreas já desflorestadas. Some-se a essa ação, a restrição ao crédito, que entrou em vigor após a publicação da Resolução n. $-3545 / 08$ do Conselho Monetário Nacional (MOURA et al., 2017; MELLO; ARTAXO, 2017). Durante a sua vigência, 2,9 bilhões não foram cedidos como crédito rural.

Em 2011, o governo do estado do Pará criou outro mecanismo mitigador do desmatamento, o "Programa Municípios Verdes", de caráter subnacional, cujos objetivos são quatro: 1) Controle e combate ao desmatamento; 2) ordenamento territorial e fundiário; 3) produção sustentável; e 4) gestão ambiental compartilhada. No ano de 2012, o novo Código Florestal (Lei n.․ 12.651/12), modificado pela Lei $\mathrm{n} . .912 .727 / 12$, trouxe em seu bojo (art. 18, $\S 4^{\circ}$ ) a criação de Cadastro Ambiental Rural único (CAR) no Sistema Nacional de Informações sobre Meio Ambiente (SINIMA), obrigatório para todos aqueles imóveis rurais (FREIRE JÚNIOR; INÁCIO, 2017). Todavia, com tantas ferramentas disponíveis, por que ocorre a supressão vegetal na Amazônia de forma frequente?

Para melhor entender o desmatamento, Santos et al. (2017), apresentam dois aspectos importantes para essa ocorrência: 1) a necessidade do desmate, devido a algumas áreas, após o desflorestamento, serem abandonadas e degradadas; e 2) o questionamento se tal ação é desejável ou não, porque os custos ambientais e sociais são elevados, porém, o retorno econômico é baixo. Na visão do Ministério do Meio Ambiente (MMA), o desflorestamento é uma prática corriqueira que faz a retirada da vegetação nativa através do corte e queima, para uso e ocupação do solo (MMA, 2018); o que, de acordo com pesquisas do Instituto Nacional de Pesquisas Espacial (INPE, 2019), contribuiu para o avanço do "arco do desmatamento" nos últimos 12 anos, como em 2006, que registrou a maior taxa de desmatamento na Amazônia Legal Brasileira (14. $\left.286 \mathrm{~km}^{2}\right)$ na última década.

O arco de desmatamento, de acordo com o relato de Farias et al. (2018), surgiu com o declínio da cobertura vegetal a partir do estado do Acre, em sua porção ocidental, perpassando pela transversal sul do estado do Pará e do Amazonas, norte do Mato Grosso, e de Rondônia, até atingir as fronteiras de três estados, Maranhão, Pará e Tocantins, quando assume a forma de um arco. É nessa área que a exploração madeireira apresenta maior frequência para atender 0 mercado consumidor.

Porém, a ação do desmatamento, seja na área geográfica do arco ou fora dele, traz inúmeras consequências negativas ao ambiente, dentre 
elas, destacam-se as mudanças climáticas e as alterações na paisagem em florestas tropicais. Ademais, sabe-se que essas alterações interferem na biologia da regeneração de biomas e, consequentemente, comprometem os serviços ecossistêmicos (Ex.: provisão e regulação da temperatura do ar; retenção de umidade, dentre outros) para as próximas gerações (FEARNSIDE, 2006; NOBRE et al., 2016; RUBIRA, 2016).

Todas essas alterações, de acordo com estudos pretéritos (FIGUEROA; NOBRE, 1990; FISCH; MARENGO; NOBRE, 1998) incrementam a ação do evento climático El Niño (WITHEY et al., 2018), o que causa impacto na agricultura familiar (LOUZADA, 2019). No ano de 2015, tal evento foi associado a ciclos oceânicos, e originou uma severa seca que assolou boa parte do território nacional e contribuiu para um aumento de $35 \%$ de incêndios florestais (ASHER, 2018).

Na região Norte, o estado do Pará apresenta a maior dinâmica quanto ao desmatamento. Nesse estado, em 2014, a taxa da supressão vegetal alcançou $1.829 \mathrm{~km}^{2}$ (INPE, 2014). Acerca desse fato, Moura et al. (2017) relataram que, em 2016, a cobertura vegetal nativa representava $76 \%$ da área territorial $(70 \%$ florestas densas; $6 \%$ vegetação nativa), da qual $21 \%$ do território estadual já foi desmatado, sendo $3 \%$ em corpos hídricos. Além disso, os autores verificaram que o desflorestamento ocorrido em 2004 também foi elevado, enquanto houve uma tendência à diminuição entre 2005 e 2012, e ao aumento, de 2014 a 2016 (Figura 1).

\section{Figura 1: Análise do desmatamento ocorrido no estado do Pará entre 2000 a 2016}

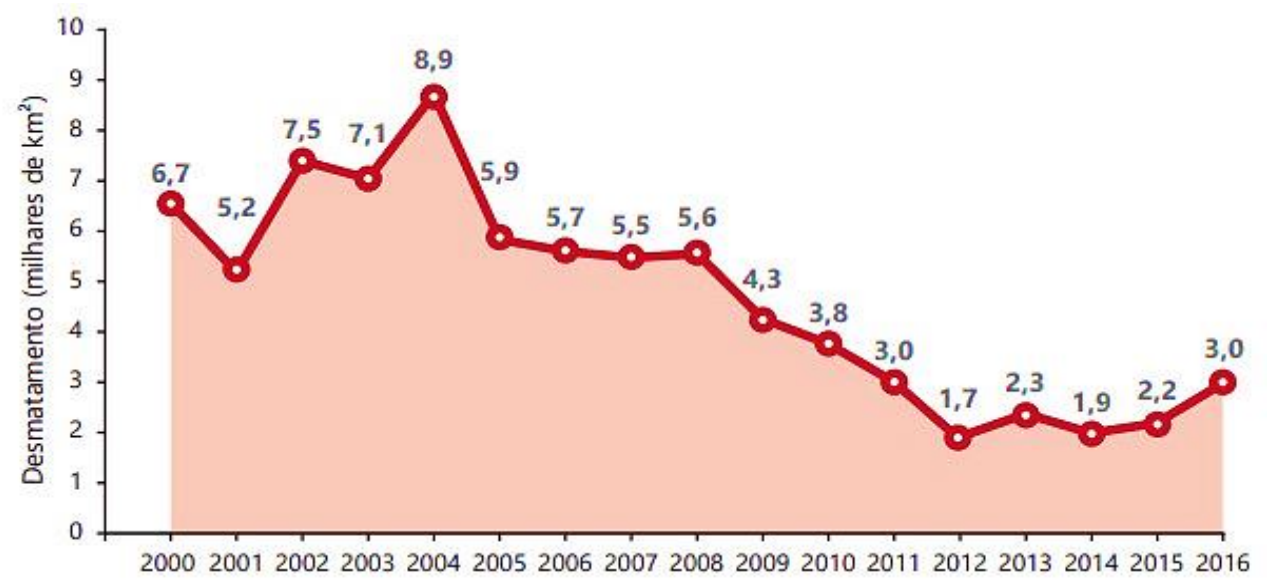

Fonte: Moura et al. (2017).

Foram identificados sete fatores contribuintes para essa evolução: produção de soja, 65,8\%; criação de bovinos, $66,5 \%$; indústria extrativista $(77,6 \%)$; silvicultura $(74,4 \%)$; indústrias diversas (85,6\%); construção (65,5\%), e 68,1\% para o setor de serviços (DOMINGUES; CARVALHO; MAGALHÃES, 2013). Devido à extensão territorial do Pará, os 143 municípios foram alocados em 12 grupos então denominados de "regiões de integração".

De acordo com a Secretaria de Planejamento do Estado do Pará (SEPLAN, 2016), há duas regiões que compõem a sub-bacia do rio Itacaiúnas: 1) Araguaia (Água Azul do Norte; Sapucaia e Xinguara); e 2) Carajás (Canaã dos Carajás, Curionópolis, Eldorado do Carajás,
Marabá, Parauapebas, Piçarra, São Geraldo do Araguaia). Vale ressaltar que o contexto da regionalidade no Pará, de acordo com Alves et al. (2018), surgiu em 2008, após a promulgação do Decreto n.⒈006/09. O objetivo de "regiões de integração" é promover uma representação de similaridades quanto à ocupação e ao nível social e econômico. Dentre essas regiões, tem-se a de Carajás (Figura 2).

Nessa região de integração, o MMA/ICMBio (2019), através da Portaria 418/2019, implantaram, via decretos federais, seis áreas de proteção: 1) Área de Proteção Ambiental (APA) do Igarapé do Gelado, Decreto n. 97.718/89; 2) Reserva Biológica do Tapirapé, n.ำ 97.719/89; 3) Floresta Nacional do Tapirapé-Aquiri, n.ำ 
97.720/89; 4) Floresta Nacional de Itacaiúnas, n.ํㅜ 2.480/98; 5) Floresta Nacional de Carajás, n.ำ 2.486/98; e 6) Parque Nacional dos Campos Ferruginosos, que abrange os municípios de Canaã dos Carajás e Parauapebas, decreto $s / n$, de 2017.

Além destas, o município de São Geraldo do Araguaia apresenta uma APA que, de acordo com a Secretaria de Estado de Meio Ambiente e Sustentabilidade (PARÁ, 1998), foi criada pela Lei ordinária $\mathrm{n} . \stackrel{0}{5.983 / 96}$ que, nos arts. $1^{\circ}$ ao $6^{\circ}$, estabelece proibições, como, por exemplo, no art. 3 , "o exercício de atividades capazes de provocar erosões das terras ou assoreamentos das condições hídricas". O problema é que o desmatamento provoca tudo isso, mas não se consegue uma solução.

Todas essas ações visaram à proteção ambiental devido à riqueza econômica dessa região, já que as atividades extrativistas e comerciais nela exercidas apresentam algumas das principais commodities do país. Tais atividades estão ligadas aos setores de agropecuária, exploração mineral, extração vegetal e serviços de beneficiamento de ferro gusa, os quais necessitam de alto consumo de lenha para geração de energia aos fornos (SANTOS et al., 2017; SEPLAN, 2016; SOUZA FILHO, 2016).

Quanto às florestas e reservas dessa região, Raiol et al. (2009) efetuaram estudos agroambientais e concluíram que há pressão para ocupação e desflorestamento por parte dos posseiros de terras que já foram documentadas e ocupadas, além de terras públicas federais, onde há presença de pequenos e grandes grupos extratores de madeira. Os autores também verificaram que as terras indígenas dos Caetés, a oeste do município, sofrem com ações do mesmo grupo. Já na reserva indígena do Sororó, a pressão vem dos assentados em áreas de conflitos referentes à extração madeireira e mineral.

Figura 2: Região de Integração do Carajás e os municípios componentes.

\section{Sudeste do Pará}
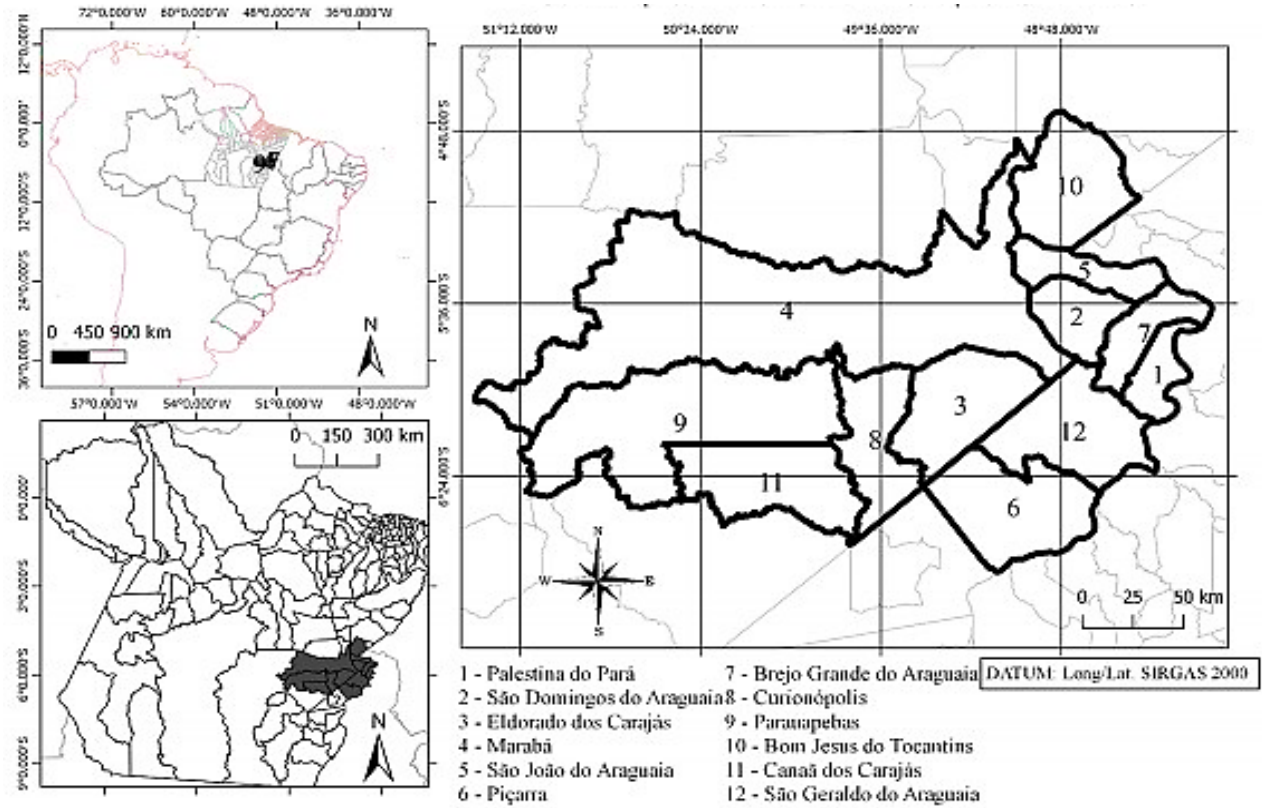

Fonte: Alves et al. (2018).

Em relação à bovinocultura, em 2017, de acordo com a Secretaria de Estado de Desenvolvimento Agropecuário e de Pesca (SEDAP/PA, 2019), houve variações quanto ao número de cabeças (em número de mil) nos municípios de Canaã dos Carajás (212.903), Curionópolis (256.321), Eldorado do Carajás
(339,704), Marabá (1.025.124), Parauapebas (119.800) e São Geraldo do Araguaia (398.801). Segundo Lobato (2019), nesses municípios, com exceção de São Geraldo do Araguaia, além da pecuária, ocorreu o uso dos recursos florestais madeireiros para produção de carvão (14.125t), lenha $\left(47.650 \mathrm{~m}^{3}\right)$ e madeira em tora $\left(31.400 \mathrm{~m}^{3}\right)$; 
e que o município de Marabá, devido à produção de ferro gusa, necessita de maior quantidade de lenha $\left(31.500 \mathrm{~m}^{3}\right)$. Isso indica que, na região de Integração de Carajás, o desflorestamento foi acentuado para o assentamento da estrada de ferro, a fim de permitir o transporte desse tipo de ferro até o porto de embarque.

Quanto à bacia hidrográfica do rio Itacaiúnas (extensão = 1 a $250 \mathrm{~km}^{2}$ ), unidade de estudo e gestão dos recursos hídricos, estabelecida pela Política Nacional dos Recursos Hídricos (PNRH), Lei n.o 9.433 (BRASIL, 1997), e sua vegetação natural, Cruz (2010) efetuou uma avaliação geoambiental e hidrológica, tendo identificado que ela está localizada na região hidrográfica estadual do Tocantins-Araguaia e possui vegetação constituída por Florestas (Ombrófila Densa Submontana; Aberta Submontana; Densa de Terras Baixas; Densa Montana) e Savana Estacional Parque, o que permite a exploração madeireira pela diversidade vegetal ofertada.

Em relação à sub-bacia, Rosa (2011) a define como uma unidade da bacia que permite a identificação de problemas difusos (o desmatamento, por exemplo), bem como do comprometimento que esses impactos causam à qualidade ambiental, ao habitat e à perda da diversidade, especialmente a vegetal.

Quanto à sub-bacia do rio Itacaiúnas, Serrão (2018) relata que ela é de "ordem 3", classificação esta efetuada pela Resolução do Conselho Nacional dos Recursos Hídricos (CNRH) n. - 030/02 que, inclusive, determinou a sua extensão: $42.000 \mathrm{~km}^{2}$. A sub-bacia nasce na Serra da Seringa, município de Água Azul do Norte, com a junção de dois rios: D'Água Preta e Rio Azul. Tem como afluentes principais os rios Parauapebas, Vermelho, Tapirapé, Sororó e Preto, e a foz está localizada na margem esquerda do rio Tocantins, já na área urbana de Marabá.

Nesse contexto, os municípios de Marabá e Parauapebas, que são componentes da sub-bacia do Rio Itacaiúnas, destacam-se pela aptidão de fornecimento de matéria-prima ou insumos às indústrias produtoras de bens de consumo. A região de Carajás, por exemplo, devido às atividades de mineração, engloba os principais municípios economicamente dependentes dessa atividade na região sudeste paraense, além de Canaã dos Carajás, Curionópolis, Marabá, Ourilândia do Norte, Parauapebas e São Félix do Xingu (PALHETA et al., 2017; ROLNIK; KLINK,
2011).

Com relação aos sete municípios da região Sudeste do estado, Craveiro (2013) afirma que eles ainda são fornecedores de matéria-prima, especialmente minerais; por isso, devem estar sujeitos a monitoramentos constantes; porém, a continentalidade na Amazônia é um fator limitante para tal. Para cessar esse limite, é necessário o uso de tecnologias espaciais com captura de imagens e elaboração de cartografias que exponham as principais informações, tanto para o monitoramento quanto para o controle do desmatamento, especialmente em Unidades de Conservação, Áreas de Reserva Legal e Áreas de Proteção Ambiental.

Acerca do uso desse recurso na sub-bacia do Itacaiúnas, Souza-Filho et al. (2015) o empregaram para identificar a mudança da cobertura vegetal, onde a floresta foi retirada ou surgiu nova vegetação, como as Savanas, e que originou áreas de pasto, agrícolas e solos desnudos. Os autores também constataram o surgimento de áreas de exploração mineral e regeneração, devido à presença de savanas montanhosas.

Sobre essas modificações ambientais, Ferreira e Pasa (2015) afirmaram que as necessidades humanas estão associadas ao uso e cobertura da terra e do solo, os quais sofrem alterações que podem interferir no clima, nos cursos dos rios e nas bacias hidrográficas, provocando secas e enchentes, ou ainda incêndios, causados por ações humanas, como, por exemplo, usos múltiplos e exploração dos recursos florestais.

Para identificar todas essas ações, mensurá-las e ainda gerar dados para a elaboração de políticas e fiscalizações ambientais, o uso de tecnologias se faz necessário, dentre elas, tem-se o geoprocessamento. Para Silva (2016), essa ferramenta apresenta-se efetiva no caso de tomadas de decisões e inclusões de conhecimentos em pesquisas ambientais, e de planejamento das gestões ambientais, ambos baseados em dados registrados de fenômenos que sejam integrativos.

Segundo estudos já efetuados com essa tecnologia (ITO et al., 2017; MARTINS et al., 2017; TORRES et al., 2017; ZAIDAN, 2017), o geoprocessamento é um conjunto de técnicas e métodos teóricos computacionais que relacionam dados secundários, desde coleta ao 
processamento de dados, com o objetivo de gerar novas formas visuais, sendo usado principalmente no estudo da superfície terrestre e nas soluções de problemas, aplicações no monitoramento de ocorrências de incêndios, dinâmica territorial e perda de vegetação

Além disso, uso de Sistema de Informação Geográfica (SIG) tem fortalecido o auxílio de software na tomada de decisões em planejamento territorial $e$ ações da gestão ambiental aplicadas às políticas públicas (PAULO; SOUZA, 2011), tendo em vista que a geotecnologia é um passo para o avanço da espacialização de informações e compreensão, não só na área ambiental, mas de um conjunto de ambientes (MESQUITA et al., 2012; SILVA, 2016).

É evidente que o frequente uso dessas tecnologias tem mostrado grande auxílio em múltiplas áreas do conhecimento, pois o meio ambiente apresenta caráter multidisciplinar. Essas técnicas, por exemplo, são imprescindíveis na análise da realidade complexa que vemos com o monitoramento de áreas afetadas pela antropização (ANDRADE; CALHEIROS, 2018; CRAVO; JANZANTTI, 2018).

Para Pantoja et al. (2015), essas tecnologias podem também auxiliar o Cadastro Ambiental Rural (CAR), já que limitam e identificam as denominadas Áreas de Reserva Legal (ARL) e Área de Proteção Permanente (APP), mensurando se elas estão de acordo com o estabelecido no Código Florestal Brasileiro (CFB), inclusive, no que se refere ao capítulo I, inciso II, art. 1으, que estabelece a obrigatoriedade do registro eletrônico dos imóveis rurais, dessa forma, contribuindo para o controle do desmatamento.

Castro e Watrin (2013) afirmaram que a aplicação de tais tecnologias é importante para o monitoramento de áreas ambientais, independentemente do tamanho, e o faz de forma criteriosa porque integra inúmeras bases de dados, sejam eles biofísicos ou socioambientais, especialmente na detecção de danos ambientais, além de proporcionar melhor análise no uso e ocupação do solo.

Todos esses argumentos justificaram este estudo e incrementaram a relevância dele, porque os dados aqui gerados poderão servir como base para os órgãos competentes e aos elaboradores de leis ambientais municipais, bem como para gestores individuais ou com gestão compartilhada intermunicípios. Além disso, tais argumentos permitiram a elaboração do objetivo do estudo que foi a identificação e quantificação do desmatamento nos municípios constituintes da sub-bacia do rio Itacaiúnas ocorrido entre 2006 e 2017.

\section{MATERIAL E MÉTODOS}

\section{Área de estudo}

Localizada na porção do sudeste paraense, a unidade de planejamento hidrográfico do rio Itacaiúnas abrange os municípios de Água Azul do Norte, Canaã dos Carajás, Curionópolis, Eldorado dos Carajás, Marabá, Parauapebas e microrregiões de São Geraldo do Araguaia, Sapucaia, Piçarras e Xinguara (Figura 3).

Desse modo, essa sub-bacia pertence à região hidrográfica do Tocantins-Araguaia, compreendendo cerca $3,30 \%$ do estado do Pará (PENEREIRO; MARTINS; BERETTA, 2016). Consideraram-se, como parâmetro, os meses de junho a outubro, pois, nesse período, na região estudada, registra-se uma baixa umidade, ausência de precipitação, pouquíssimas nuvens, elevação das temperaturas, o que facilita a captação de imagens em local que sofreram desflorestamento (ABREU; SOUZA, 2016).

Outro parâmetro a se considerar é o fato de - rio Itacaiúnas apresentar as principais características geomorfológicas (como as formas e os tipos de relevo) presentes em uma sub-bacia, como: afluência que se dá à margem esquerda do rio Tocantins, confluência com o rio Araguaia, $42.000 \mathrm{~km}^{2}$ de extensão e altitude máxima de 300 m (MESSIAS; FERREIRA, 2014; OTI; EWUSI, 2016; SILVA JÚNIOR, 2017). Essa área da unidade hidrográfica dispõe de duas tipologias de floresta dominante: a floresta ombrófila densa e a aberta, características estas do bioma Amazônico (VIANA; GIL, 2018). A área enquadra-se, ainda, na classificação Köppen-Geiger, como tipo "Aw" e "Am", típico de clima tropical e tropical úmido, com temperatura média acima de $22^{\circ} \mathrm{C}$, período seco prolongado e chuvoso definido (ALVARES et al., 2014; DUBREUIL et al., 2018).

Sabe-se, também, que as sub-bacias hidrográficas são como uma unidade básica, para que haja o planejamento de ecossistemas, ou seja, afirmam a existência de uma relação interdependente dos meios físico, biológico e antrópico (CARPENTER et al., 2015). Desse modo, a sub-bacia do rio Itacaiúnas, durante o 
processo de ocupação e exploração, contribuiu intrinsicamente com o desenvolvimento regional do sudeste do estado do Pará (SOUZA FILHO et al., 2016).

Figura 3. Localização da Sub-Bacia Hidrográfica do Rio Itacaiúnas. Sudeste do Pará

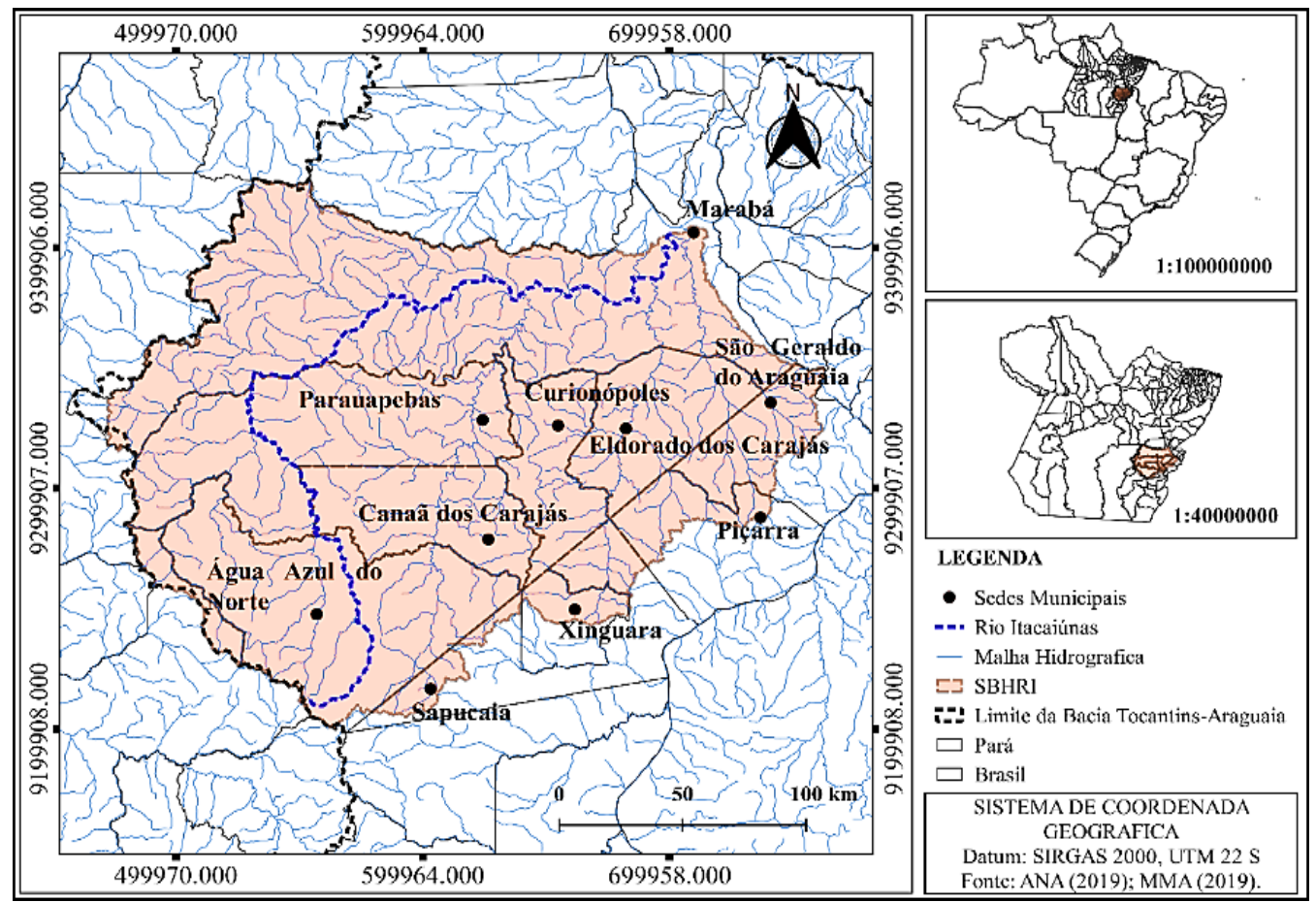

Fonte: Autores (2019).

\subsection{Delineamento da pesquisa}

O método aplicado no delineamento da pesquisa foi o dedutivo, que parte da observação sistemática da premissa e por tentativas de experimentar as conjecturas e eliminar erros (VIEIRA et al., 2017). Também, foi possível desenvolver a pesquisa com caráter exploratório de natureza aplicada, com abrangência quantiqualitativa (MARCONI; LAKATOS, 2017). Os dados pretéritos foram obtidos em sites de busca com acesso aberto, tais como Coordenação de Aperfeiçoamento de Pessoal do Ensino Superior (CAPES), Google Scholar, Scientific Eletronic Library Online (SciELO), Science Directe Web Science (Quadro 1).

\section{Coleta, processamento e análise dos dados}

Para o desenvolvimento desta pesquisa, foram utilizados dados tabulares disponíveis de forma gratuita em plataformas digitais governamentais. Os arquivos de desflorestamento são de origem do Programa de Detecção de Desmatamento em Tempo Real (DETER). O limite da sub-bacia do rio Itacaiúnas e a malha hidrográfica foram obtidos na Agência Nacional de Águas (ANA), enquanto os arquivos de limite municipais foram coletados no Ministério do Meio Ambiente (MMA), todos tratados na plataforma gratuita QGIS 3.4 Itr. Efetuou-se a coleta nos arquivos e links oficiais abertos (Quadro 2).

Os valores de números das áreas desflorestadas são coletados pelo satélite Terra, que é possível detectar alterações na cobertura florestal com áreas maiores que 25 hectares, abordo dos sensores MODES para os anos de 2006 a 2017. Em seguida, esses dados foram reprojetados para o Sistema de Coordenadas Geográficas (SIRGAS, 2000), com arquivos de dados geoespaciais em forma de vetores (Shapefile) pela função salvar feições como.

Para quantificar tais dados, procedeu-se a separação dos valores, em $\mathrm{km}^{2}$, para o período analisado (2006 a 2017), a cada ano, e, em seguida, foram alocados em planilhas eletrônicas do software Excel, versão 2010. Logo após, definiram-se as séries temporais em 12 anos, sublocadas em quatro intervalos trienais, o que proporciona a elaboração de mapas de visualização de Kernel (2006-2008, 2009-2011, 2012-2014, 2015-2017). 
Vale ressaltar que a gênese da palavra Kernel, em termos de geotecnologia, significa identificação do núcleo e refere-se ao processo estatístico da estimação de curvas de densidade, além de permitir a ponderação de cada observação ocorrida a partir da ponderação entre a distância e o valor central, ou seja, o núcleo. Além disso, exprime os padrões do comportamento geográfico, porque é plotada a intensidade do desflorestamento nos locais onde ele ocorre (VIEIRA et al., 2018)
Decidiu-se pelo uso do algoritmo estimador/determinador de densidade por ser um método simples e eficaz para análise do comportamento de padrões de pontos, e calcula a ocorrência do evento espacial da área de estudo. Além disso, a função realiza a contagem da distribuição de todos os pontos dentro do raio de influência, examinando a distância entre cada ponto em relação ao centro (CÂMARA; CARVALHO, 2002). Assim os dados matriciais de desflorestamento foram organizados em tabelas no Software Excel, versão 2013.

\section{Quadro 1: Principais sites de busca utilizados para obtenção de dados}

\begin{tabular}{|c|c|}
\hline SITE & TIPO DE ARTIGO \\
\hline $\begin{array}{l}\text { Coordenação de } \\
\text { Aperfeiçoamento de Pessoal } \\
\text { do Ensino Superior (CAPES) }\end{array}$ & $\begin{array}{l}\text { Artigos nacionais que desenvolveram pesquisa na área de } \\
\text { desflorestamento e queimadas na região sudeste do Pará e na } \\
\text { região da Amazônia Legal Brasileira e análise estatística anova e } \\
\text { tratamento de Token }\end{array}$ \\
\hline $\begin{array}{l}\text { Scientific Electronic Library } \\
\text { Online (SciELO) }\end{array}$ & $\begin{array}{l}\text { Artigos internacionais sobre as práticas de desflorestamento e } \\
\text { queimadas na região amazônica brasileira }\end{array}$ \\
\hline Science Direct & $\begin{array}{l}\text { Artigos internacionais que utilizaram das ferramentas de } \\
\text { geoprocessamento como a intensidade Kernel }\end{array}$ \\
\hline
\end{tabular}

Fonte: Autores (2020).

Quadro 2: Objetos de busca e links utilizados para localização e a obtenção dos dados utilizados. Marabá - PA

\begin{tabular}{|c|c|c|c|}
\hline Dados & Local de busca & DATUM & Escalas \\
\hline $\begin{array}{l}\text { Sapeie da sub- } \\
\text { Bacia } \\
\text { hidrográfica do } \\
\text { rio Itacaiúnas }\end{array}$ & $\begin{array}{l}\text { Agência Nacional de Águas (ANA). Link: } \\
\text { <http://dados.gov.br/dataset/unidade-de- } \\
\text { planejamen to-hidrico1> }\end{array}$ & WGS 84 & -- \\
\hline $\begin{array}{l}\text { Shapefile } \\
\text { do } \\
\text { desmatamento }\end{array}$ & 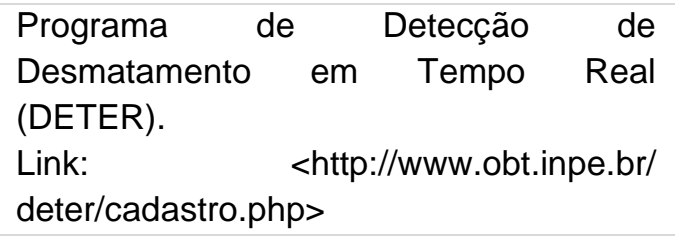 & $\begin{array}{l}\text { GRS } \\
1980 \\
\text { elipsoid } \\
\text { e }\end{array}$ & -- \\
\hline $\begin{array}{l}\text { Shapefile } \\
\text { de corpos } \\
\text { hídricos }\end{array}$ & $\begin{array}{l}\text { Agência Nacional de Águas (ANA). Link: } \\
<\text { http://metadados.ana.gov.br/geonetwor } \\
\text { k/srv/pt/main.home > }\end{array}$ & WGS 84 & $1: 1.000 .000$ \\
\hline $\begin{array}{l}\text { Shapefile } \\
\text { do limite } \\
\text { municipal }\end{array}$ & $\begin{array}{l}\text { Ministério do Meio Ambiente (MMA). } \\
\text { Link:< } \\
\text { http://mapas.mma.gov.br/i3geo/datadown } \\
\text { load.htm> }\end{array}$ & SAD 69 & $1: 100.000$ \\
\hline
\end{tabular}

\section{Tratamento estatístico}

Os dados alfanuméricos obtidos dos arquivos em formato shapefile para o desflorestamento dos meses de junho e outubro do período compreendido entre 2006 a 2017, foram 
submetidos a análise de variância (ANOVA) de fator único e Teste de Tukey, para verificar a diferença significativa em $5 \% \quad(p<0,005)$, e classificá-los em três grupos: $A, A B$ e B. Já a linha de tendência linear foi adaptada a partir do estudo para verificar a expectativa da evolução e regressão da área desflorestada no período analisado (WHITE; WHITE, 2016). Esse tratamento foi desenvolvido no software Action Start versão 3.6 e Microsoft Excel (ACTION, 2019).

\section{RESULTADOS E DISCUSSÃO}

A análise dos dados obtidos indicou a ocorrência de $276,4862 \mathrm{~km}^{2}$ de área desflorestada, no período de junho a outubro dos anos de 2006 a 2017 na sub-bacia estudada, sendo registrado, no período de 2006 a 2008 o maior índice ( $n=162,1007 \mathrm{~km}^{2} ; 58,63 \%$ ) de área desflorestada, enquanto o período de 2012-2014 ( $n=15,932 \mathrm{~km}^{2}$; $5,76 \%$ ) ocorreu uma diminuição (Tabela 1).

Acerca do desflorestamento no período analisado, na pesquisa realizada por Vilela e Bueno (2016) nas seis mesorregiões que constituem o estado do Pará, na região sudeste, havia uma elevada taxa de desmatamento $(n=$ $136.842 \mathrm{~km}^{2}$ ), quando comparado com as outras regiões, como, por exemplo, a nordeste $(n=$ $46.896 \mathrm{~km}^{2}$ ), em 2016.

Quanto aos dois últimos trimestres, a análise dos dados indicou que houve uma evolução do terceiro para o quarto trimestre $(\mathrm{n}=$ $17.283 \mathrm{~km}^{2}$ ), a qual foi objeto de pesquisa realizada por Moura et al. (2017). Segundo esses autores, tal incremento $(n=+38 \%)$ está associado a impunidades de crimes ambientais elevadas, perda de especialistas em análise ambiental $(n=-$ $40 \%$ ), problemas ocorridos com os pecuaristas, em que $30 \%$ dos açougues localizados na Amazônia não assinaram acordos quanto ao uso de áreas já desmatadas.

Em relação à análise dos dados por município, foi indicado que o município de Marabá apresentou, no primeiro triênio analisado, a maior área devastada, enquanto em Piçarra e São Geraldo do Araguaia, mantiveram-se as florestas intactas, já que não foram detectadas imagens que indicassem o desflorestamento (Tabela 2).

Tabela 1: Registro do desflorestamento e o total, em km2, no período de 2006 a 2017

\begin{tabular}{lll}
\hline Triênios & Área Desflorestada $\left.\mathbf{( k m}^{2}\right)$ & Evolução \\
\hline $2006-2008$ & 162,100 & -- \\
\hline $2009-2011$ & 65,234 & $-96,866$ \\
\hline $2012-2014$ & 15,934 & $-49,300$ \\
\hline $2015-2017$ & 33,217 & +17.283 \\
\hline Total & 276,486 & \\
\hline Fonte: Autores (2020).
\end{tabular}

Tabela 2: Registro do desflorestamento no período de 2006 a 2017 para os municípios componentes da sub-bacia do rio Itacaiúnas. Marabá - PA

\begin{tabular}{|c|c|c|c|c|c|c|c|}
\hline Municípios & $\begin{array}{l}2006 \\
2208\end{array}$ & a & $\begin{array}{l}2009 \\
2011\end{array}$ & a & $\begin{array}{l}2012 \\
2014\end{array}$ & $\mathbf{a}$ & 2015 a 2017 \\
\hline Água Azul do Norte & 22,0 & & 27,0 & & 6,0 & & 20,0 \\
\hline Canaã dos Carajás & 0,3 & & 2,0 & & 8,0 & & 4,0 \\
\hline Curionópolis & 3,2 & & 0,0 & & 0,0 & & 1,0 \\
\hline $\begin{array}{l}\text { Eldorado dos Carajás } \\
\text { Marabá }\end{array}$ & $\begin{array}{l}0,8 \\
113,1\end{array}$ & & $\begin{array}{l}33,0 \\
55,0\end{array}$ & & $\begin{array}{l}0,0 \\
10,0\end{array}$ & & $\begin{array}{l}2,0 \\
34,0\end{array}$ \\
\hline Parauapebas & 13,5 & & 8,0 & & 2,0 & & 3,0 \\
\hline Piçarra & 0,0 & & 0,0 & & 0,0 & & 0,0 \\
\hline $\begin{array}{l}\text { São Geraldo do } \\
\text { Araguaia }\end{array}$ & 0,0 & & 0,0 & & 0,0 & & 0,0 \\
\hline Sapucaia & 5,0 & & 0,0 & & 0,0 & & 4,0 \\
\hline Xinguara & 4,2 & & 1,0 & & 1,0 & & 0,0 \\
\hline
\end{tabular}


Após aplicação do tratamento estatístico Análise de Variância (ANOVA) e o teste de Tukey, verificou-se que as médias apresentaram diferença significativa no desflorestamento $(\mathrm{F}=2,86 ; p<0,03)$, nos períodos trienais de 20062008 e 2012-2014, classificando-os em grupos distintos de A, AB e B (Figura 4).

Os dados obtidos e analisados indicaram que, no período de 2006 a 2014, o desflorestamento nessa região mostrou tendência à diminuição. Porém, no último trimestre, a tendência foi de elevação. Acerca da elevação da perda vegetal, Mello e Artaxo (2017) analisaram que a ação do PPCDam trouxe resultados positivos na contenção do desmatamento, e que as crescentes taxas de desmatamento acarretam graves impactos ambientais e socioeconômicos, além de mudanças de uso do solo. Ambos os aspectos abordados por esses pesquisadores foram identificados no estudo da sub-bacia do rio Itacaiúnas.

Dentre os períodos analisados, o de 20062008 (Figura 5a) foi o de maior taxa do desmatamento. Essa alteração, segundo Santos et al. (2017), justifica-se pelo progresso da mesorregião do sudeste paraense, mediante o uso de atividades de agropecuária extensiva, como soja (Glycine max [L] Merril), eucalipto (Eucalyptus sp.) e o rebanho bovino. Já 2009-2011 (Figura 5b) e 2012-2014 (Figura 5c), houve uma redução de $83 \%$ no índice de desflorestamento, caracterizando assim uma tendência de regressão na região da sub-bacia. No entanto, no período de 2015-2017 (Figura 5d), constatou-se uma elevação de $39 \%$ de área desflorestada por exploração mineral e madeireira.

Acerca desses dados, na pesquisa da Fapespa (2017), em 2008, a produção agropecuária no estado do Pará alcançou 14.635 ha de área para pastagem, com crescimento contínuo até 2014 ( $n=16.62$ ha; 17,32\%). Houve também indicação dos municípios de Marabá e Água Azul do Norte, os quais ocupam o $2^{\circ}$ e o $7^{\circ}$ lugar, respectivamente, pois ambos são os dois maiores produtores de rebanho bovino do estado. Por essa razão, a derrubada da vegetação corrobora com a degradação ambiental na região. Sobre isso, Souza-Filho et al. (2015) efetuaram estudo na sub-bacia do rio Itacaiúnas, em Marabá/PA, e concluíram que a maior parte $(n$ $=41 \%$ ) dessa área foi convertida em pasto e uma pequena parte $(n=8 \%)$ não foi inalterada.

Figura 4: Médias trienais do desflorestamento: 2006 a 2017. Sudeste do Pará

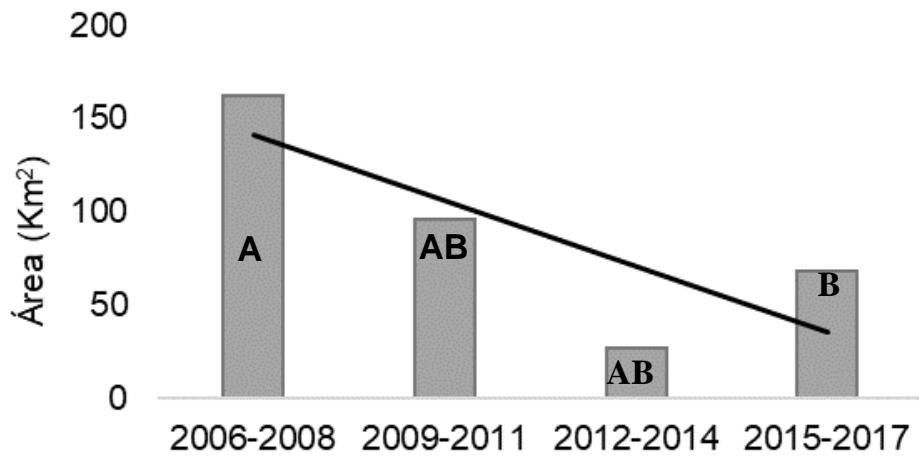

Fonte: Autores (2020).

Uma visão mais ampla foi exposta na revisão bibliográfica efetuada por Santos, Souza e Araújo (2018), quando os autores relatam que os empreendimentos que abrangem mineradoras, setor frigorífico, monocultura de soja, eucalipto e o comércio, nos municípios de Marabá, Parauapebas e Canaã dos Carajás, são os principais atrativos da região, os quais intensificaram 0 fluxo migratório, 0 desenvolvimento urbano desordenado e, consequentemente, alterou o uso e ocupação do solo e a paisagem, de natural para urbana.

No estudo efetuado por Mello e Artaxo (2017) sobre a "evolução do Plano de ação para prevenção e controle do desmatamento na Amazônia Legal", os autores concluíram que, entre 2006 a 2008, o INPE registrou, em média, cerca de $18.100 \mathrm{~km}^{2}$ desmatados nessa área. Já na visão do Instituto Terra Brasilis (BRASIL, 2019), esse foi o segundo maior índice detectado desde o início das ações de fiscalização e controle do desmatamento, em $2004\left(n=27.772 \mathrm{~km}^{2}\right)$, pelo 
Sistema de Detecção do Desmatamento em Tempo Real (DETER) e Prevenção e Controle do Desmatamento na Amazônia Legal (PPCDAm). Esses dois órgãos intensificaram as ações de prevenção contra o desmatamento, o que resultou em redução significativa $(80 \%)$ de pontos de desflorestamento na região amazônica, até o ano de 2012 (DELAZERI, 2016; MOURA et al., 2017).

Figura 5: Mapas do desflorestamento entre: a) 2006 e 2008; b) 2009 e 2011; c) 2012 e 2014; d) 2015 e 2019. Sudeste do Pará
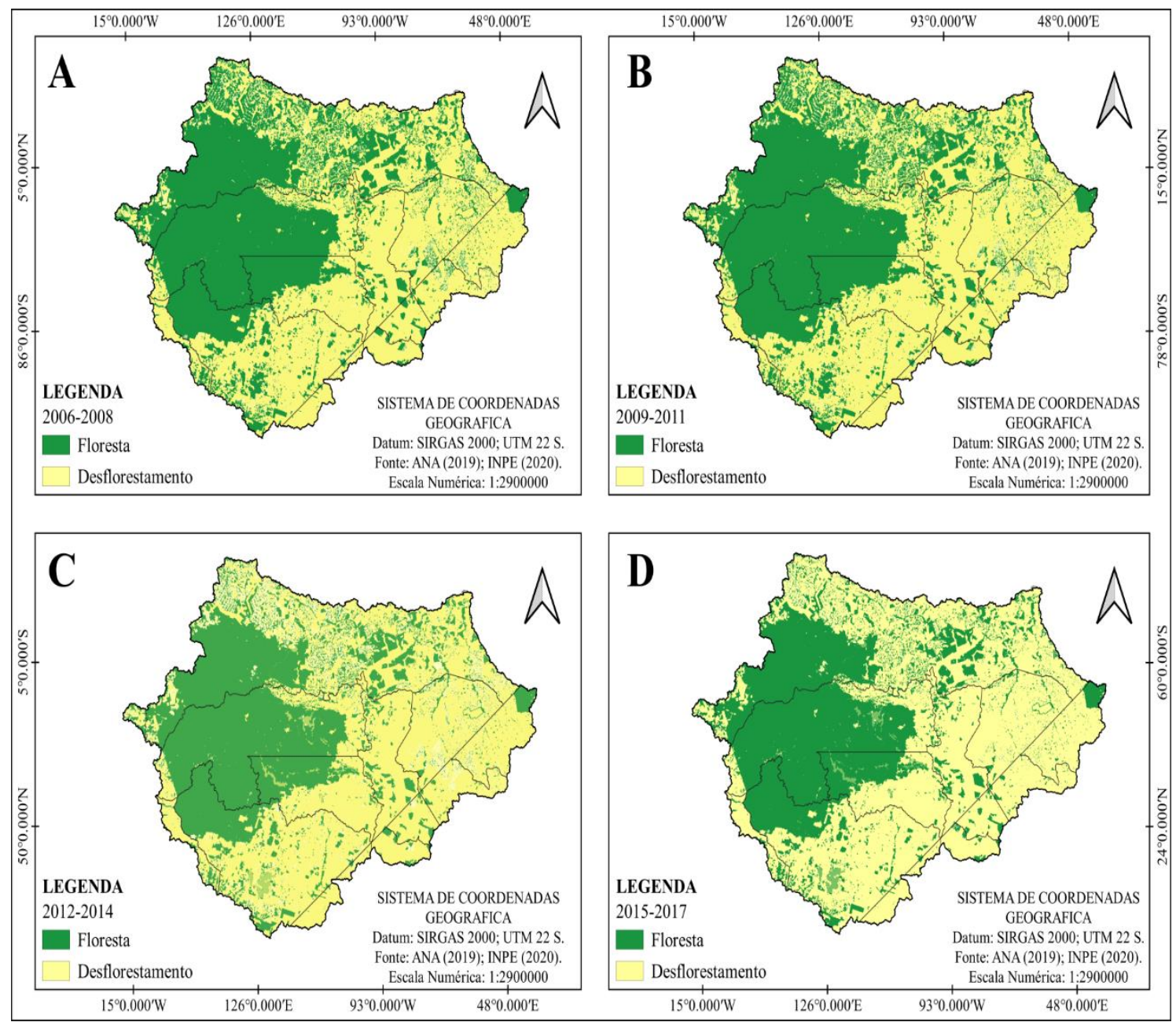

Fonte: Autores (2020).

Quanto às fiscalizações e controles, Matos (2016) realizou pesquisa acerca da relação entre a lavratura de autos de infração (IBAMA) e as taxas de desmatamento (PODES/INPE), e constatou que houve uma redução na supressão vegetal devido à lavratura e à presença de órgãos de fiscalização, além da criação de Unidades de Conservação (UC's) em municípios com alta incidência de desmatamento. Tais ações proporcionaram redução à tendência de degradação por desflorestamento no período de 2009 a 2014.

No entanto, no período de 2015 a 2017, houve uma tendência à evolução no índice de desflorestamento $\left(n=33,2 \mathrm{~km}^{2} ;<100 \%\right)$ quando comparado ao período anterior, ou seja, 2012-2014 ( $\left.n=15,9 \mathrm{~km}^{2} ; 5,7 \%\right)$. Sobre essas variações, o estudo efetuado por Villela e Bueno (2016), acerca do desmatamento no estado do Pará, por mesorregiões, concluiu que a mesorregião sudeste apresentou maior índice (136.842 km²) entre 2000 e 2014. Logo, os dados obtidos nesta pesquisa corroboraram com os obtidos por Vilela e Bueno.

$\mathrm{Na}$ análise de cada município componente da sub-bacia do rio Itacaiúnas, verificou-se que em Água Azul do Norte, que 
se encontra inserido no município de Parauapebas, a cobertura vegetal foi reduzida. Os dados que Mitschein et al. (2016), em seus estudos, obtiveram indicam que nessa localidade, em 2014, ocorreu uma redução de $n=-32 \%$ a $-50 \%$ da cobertura vegetal original.

Tal fato também foi comprovado na pesquisa realizada por Cabral e Gomes (2013), indicando que, entre 2008 e 2009, portanto, cinco anos antes, o crescimento anual da taxa do desflorestamento em Água Azul do Norte já se apresentava de forma negativa ( $n=-31,8 \%$ ). Isso explica a redução da cobertura, após as análises das imagens e dos quantitativos encontrados para o período analisado de 2009 a 2011 , de $162.100 \mathrm{~km}^{2}$ para $65.234 \mathrm{~km}^{2}$.

Nesse município, com o Projeto Pedra Branca, de 2018, determinado a explorar cobre $(\mathrm{Cu})$, ouro $(\mathrm{Au})$ e prata $(\mathrm{Ag})$, da Companhia Vale, esperavam-se intervenções na vegetação, fauna, APP's, qualidade do ar, ruídos e vibrações, topografia e processos erosivos. Sobre esse projeto, a Secretaria Estadual de Meio Ambiente e Sustentabilidade (SEMAS, 2018) publicou, no Relatório de Impacto Ambiental (RIMA), que a vegetação e a fauna sofreriam impacto de grau alto. Como previsto, o desflorestamento foi incrementado nesse município.

Já em Canaã dos Carajás, no estudo efetuado por Cortez, Sá e Pereira Junior (2019), os autores obtiveram dados que os permitiram afirmar que, entre 2008 a 2012, houve um respeito ao limite geográfico, constituído pela Floresta Nacional (FLONA), que ocupa 1.190,9 $\mathrm{km}^{2}$ do território desse município, pois o desflorestamento diminuiu ( $n$ $\left.=1.670,53 \mathrm{~m}^{2} ; 53,10 \%\right)$. Os autores explicaram que isso ocorreu em função de dois fatores: 1) aumento na fiscalização e controle do desmatamento e, 2) o programa de reflorestamento utilizado pela mineradora Vale, nessa área.

$\mathrm{Na}$ pesquisa realizada nesse mesmo município, por Lopes, Santos e Cruz (2018), sobre a exploração do uso e ocupação do solo e do mineral nele existente, os autores obtiveram dados que indicaram a existência de dois projetos minerais: Sossego, em operação desde 2004, e Ferro Carajás S II D, desde 2016, os quais causaram desmatamento, poluição hídrica, perda de terras agricultáveis, dentre outros eventos. Como se percebe, embora haja redução no desflorestamento, está longe de cessar, porque se mais veios minerais forem descobertos via prospecção, mais áreas serão desmatadas.

Outro município objeto dessa pesquisa foi Curionópolis que ocupa uma área igual a $2.369 \mathrm{k}^{2}(n=0,19 \%)$ do território paraense $(n=$ $\left.1.247,955 \mathrm{~km}^{2}\right)$. Manescky, Souza e Paes (2019) não identificaram presença de áreas protegidas (Uso Sustentável Federal - U.S.F. ou Estadual - U.S.E., ou de Proteção integral - P.I.) e nem Terras Indígenas (T.I), como ocorrem em Canaã dos Carajás (U.S.F; T.I) e Marabá (U.S.F.; P.I; T.I). Por isso, Curionópolis, em 2017, apresentou elevados índices de desflorestamento em relação à área que ocupa geograficamente $\left(n=2.016 \mathrm{~km}^{2}\right.$; $85 \%$ ).

Já Eldorado dos Carajás apresenta uma baixa incidência de cobertura vegetal $(n=7 \%)$ quando comparado com a área geográfica que ocupa ( $n=92.957 \mathrm{~km}^{2}$ ), com desmatamento elevado ( $n=2.751 \mathrm{~km}^{2} ; 93 \%$ ). Acerca desses dados, Silva e Costa Neto (2013) efetuaram uma análise multitemporal da cobertura vegetal nesse município com o uso do georrefenciamento, e identificaram que, entre 2005 a 2010, a taxa do desflorestamento já era elevada ( $\left.n=82.731 \mathrm{~km}^{2} ; 89 \%\right)$.

Marabá, município com maior extensão geográfica do sudeste paraense $(n=$

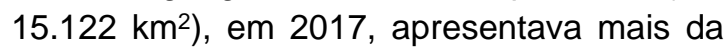
metade da área geográfica ocupada e desmatada ( $n=8.657 \mathrm{Km}^{2} ; 57,3 \%$ ). Dentre as atividades econômicas ativas nesse município, encontra-se a extração de argila, para indústria oleira, sendo necessário eliminar a vegetação antes de sua exploração. Segundo pesquisa de Mello et al. (2017), em Marabá, a eliminação da vegetação para extração de argila altera a paisagem local, eleva o número de áreas degradadas, além de aumentar a temperatura do ar. Logo, não há uma relação entre a atividade econômica e a sustentabilidade nesse município.

Em relação a Marabá, os dados analisados pelo PRODES, no período de 2006 a 2015, identificaram uma evolução de 7.541,5 $\mathrm{Km}^{2}$ para $8.533,5 \mathrm{~km}^{2}$, portanto, um avanço significativo ( $n=992 \mathrm{~km}^{2} ; 31,5 \%$ ). De acordo 
com Mengato Junior, Oliveira e Silva (2017) e Neves et al. (2014), os fatores econômicos, o declínio da exploração madeireira da castanha-do-pará (Bertholletia excelsa) e a pecuária explicam o desflorestamento intenso ocorrido nesse município no período analisado.

O segundo município de maior extensão territorial no sudeste paraense é Parauapebas $\left(n=6.886 \mathrm{~km}^{2}\right)$, onde está abrigado o Projeto Grande Carajás (PGC), cuja exploração madeireira para serrarias ainda é efetiva. Quanto a esse tipo de exploração, Luz (2018) efetuou estudo sobre 0 abastecimento madeireiro que o Pará realiza, e concluiu que a mineração promoveu a supressão vegetal no interior da Floresta Nacional de Carajás (FLONA) e "doou" para os dois polos moveleiros do município 21 espécies diferentes, dentre elas, Dipteryxodorata, Bagassaguianensis e Clarisia racemosa.

No rio que leva o mesmo nome desse município, e que é tributário do rio Itacaiúnas, o desmatamento tem sido elevado, para que se pratiquem as atividades mineradoras. Acerca dessas atividades, Siqueira, Apriles e Miguéis (2012), na pesquisa realizada no rio Parauapebas, indicaram que a retirada de seixos na calha central do corpo hídrico como insumo à construção civil é depositado em área desmatada à margem direita, onde há uma caçamba basculante que faz o transporte até o local da obra por uma estrada vicinal, resultante de desmatamento, e criada especialmente para essa exploração, o que tem provocado alterações na qualidade da água e da paisagem local.

Piçarra é considerada uma microrregião na sub-bacia do Itacaiúnas, com uma área desmatada de $n=2.925 \mathrm{~km}^{2}$ (88,2\%), quase que equivalente à sua área geográfica $(n=$ $3 ; 313 \mathrm{~km}^{2}$ ). Para justificar tal desmatamento, Souza (2014) realizou pesquisa sobre a economia ativa do local, e concluiu que, em 2010, a agricultura contribuiu com $50,2 \%$, a indústria com $8,2 \%$ e a extração madeireira com um menor valor, já que ela se destina ao fornecimento de lenha. Das propriedades rurais, em $\mathrm{Km}^{2}, 2.657$ já estão registradas no CAR, o que pode ter favorecido a estagnação do desmatamento, em 2017. Assim, esta pode ser uma das ferramentas eficazes para o controle ou, pelo menos, estagnação do desmatamento no município e sudeste paraense.

Em Sapucaia, cuja área equivale a $1.302,63 \mathrm{~km}^{2}$, prevalece a economia da pecuária de corte e produção leiteira, porém, devido à baixa incidência do rebanho, é o município que menos contribuiu para o desmatamento. Com a pesquisa que Passos e Silva (2016) realizaram neste município, as autoras concluíram que, em 2010, foram extraídos $48 \mathrm{~m}^{3}$ de madeira em toras, e que a pecuária é o fator limitante para o avanço da agricultura familiar, o que impede o reuso de áreas degradadas.

O município de São Gerado do Araguaia, cuja área geográfica equivale a $3.168 \mathrm{~km}^{2}$ ou $0,25 \%$ do território do estado (IBGE, 2010), possui uma Área de Proteção Ambiental (APA Araguaia) criada em 1996, com área igual a $27.164 \mathrm{~km}^{2}$, pela Lei $\mathrm{n} . \stackrel{0}{5.983}$ (PARÁ, 1996), com o objetivo de amortecer os impactos causados pelo desflorestamento, já que a paisagem e o uso e ocupação do solo estão totalmente alterados. Todavia, em 2017, os dados do INPE/PRODES identificaram desmatamento em área inferior a $40 \mathrm{~km}^{2}$.

Quanto ao município de Xinguara, estudo efetuado por Pereira Júnior e Dos Santos (2016) indicou que a retirada da vegetação, em 2010 - três anos depois de sua emancipação -, foi associada à construção da rodovia BR 155 e a PA 279, sendo que a zona urbana foi a área mais envolvida. Já em 2013, na pesquisa realizada por Costa e Pires (2013), foi detectada uma área de $3.374,2 \mathrm{~km}^{2}$ desflorestada.

Conclui-se que os dados coletados durante o período de 12 anos identificam a extensão do desflorestamento que o sudeste do estado do Pará sofreu e, especialmente, naqueles municípios que constituem a subbacia do rio Itacaiúnas, e que a perda da cobertura vegetal expõe o solo a lixiviação e ao assoreamento de parte da calha central.

\section{CONCLUSÕES}

Observou-se que a maior incidência de áreas desflorestadas predominou no período de 2006-2008 e a menor, em 2012-2014, 
sendo que as regiões componentes da subbacia do rio Itacaiúnas que registraram incidências muito altas concentraram-se, inicialmente, nos municípios de Marabá, São Geraldo, Eldorado dos Carajás, Piçarra, e evoluiu, no decorrer da análise temporal efetuada, para Água Azul do Norte e Canaã dos Carajás.

Percebeu-se também que no período de 2006 a 2014 houve uma tendência de regressão nos registros de áreas desflorestadas, com elevação entre os anos de 2015 a 2017, equivalente a $68 \mathrm{~km}^{2}$. A ferramenta de mapa de Kernel foi essencial para compreensão do comportamento da evolução dos casos de desmatamento, porque proporcionou uma melhor percepção das regiões com menor e maior incidência dessa ação na bacia estudada.

Mesmo com a criação de Áreas de Proteção Ambiental, de Proteção Permanente e Florestas Nacionais, o desmatamento no Sudeste não apresentou diminuição. Apesar da exigência de $A R L$, não foi observado respeito e obediência às Leis ambientais, de caráter Federal, Estadual e Municipal, em face do desenvolvimento econômico nessa região.

No município de Marabá, apesar de a presença de $80 \%$ da Reserva Tapirapé-Aquiri situar-se na área geográfica desse município, a extração de madeira para usos diversos ainda é constante. Isso também ocorre nos municípios de Canaã dos Carajás e Parauapebas, onde se encontra o Parque Campos Ferruginosos. Contudo, esses dois municípios foram os que apresentaram altas taxas de desflorestamento no período analisado.

Com este estudo, constatou-se a importância da continuidade do monitoramento frequente, para que ocorra a conservação e a preservação dessa região, pois a sub-bacia do rio Itacaiúnas é composta por municípios em constante desenvolvimento pelas atividades que impulsionam a economia do estado, como a mineração, agropecuária e, principalmente, o uso da floresta para produção de carvão lenha e madeira.

\section{REFERÊNCIAS}

ABREU, F. A.; SOUZA, J. S. A. Dinâmica espaço- temporal de focos de calor em duas terras indígenas do Estado de Mato Grosso: uma abordagem Geoespacial sobre a dinâmica do uso do fogo por Xavantes e Bororos. Revista Floram, v. 23, p. 1-10, 2016.

ACTON. Portalaction. Disponível em: http://www.portalaction.com.br/manualanova/teste-de-tukey. Acesso em: 06 set. 2019.

ALVARES, C. A.; STAPE, J. L.; SENTELHAS, P. C.; GONÇALVES, J. L. M.; SPAROVEK, G. Köppen's climate classification map for Brazil. Meteorologische Zeitschrift, v. 22, n. 6, p. 711 728, 2014.

ALVES, E. O.; QUEIROZ, B. F. P.; OLIVEIRA, N. M.; LUZ, R. A. Região de integração dos Carajás Pará: uma análise regional. ACTA Geográfica, Boa Vista, v. 12, n. 30, p. 150-171, 2018.

ANDRADE, E. L.; CALHEIROS, S. Q. Áreas potencialmente perigosas a acidentes com transporte rodoviário de produtos perigosos no trecho alagoano da Rodovia Br-101. Geo UFRJ, n. 33, 2018. Disponível em: https://www.epublicacoes.uerj.br/index.php/geouerj/article/view/2 8821/27305. Acesso em: 30 jul. 2020.

ARVOR, D.; TRISCH, I.; BARCELLOS, C.; JEGOOU, N.; DUBREULL, V. Land use sustainability on the southeast region Amazon agricultural frontier: recent progress and the challenges ahead. Applied Geography, v. 80, p. 86-97, 2017.

ASHER, C. Drought-driven wildfires on the rise in Amazon basin, upping $\mathrm{CO}_{2}$ release. Mongabay. $2018 . \quad$ Disponível em: <https://news.mongabay.com/2018/02/droughtdriven-wildfires-on-rise-in-amazon-basin-uppingco2-release/>. Acesso em: 12 fev. 2019.

BRASIL. Lei 9.433, de 08 de janeiro 1997. Instituiu a Política Nacional de Recursos Hídricos, cria o Sistema Nacional de Gerenciamento de Recursos Hídricos, regulamenta 0 inciso XIX do art. 21 da Constituição Federal, e altera 0 art. $1^{\circ}$ da Lei $n^{\circ}$ 8.001, de 13 de março de 1990, que modificou a Lei no 7.990, de 28 de dezembro de 1989. Diário Oficial da União, Poder Executivo, Brasília, 09 jan. 1997. Disponível

em:

http://www.planalto.gov.br/ccivil 03/leis/19433.htm\# : :text=LEl\%20N\%C2\%BA\%209.433\%2C\%20DE \%208\%20DE\%20JANEIRO\%20DE\%201997.\&text =Institui\%20a\%20Pol\%C3\%ADtica\%20Nacional\%2 0de, $0 \% 20$ inciso\%20XIX\%20do\%20art.\&text=1\%C2 \%BA\%20da\%20Lei\%20n\%C2\%BA\%208.001,28\% 
20de\%20dezembro\%20de\%201989. Acesso em: 01 ago.2020.

Lei $\mathbf{n} . \mathbf{9} 9.985$, de 18 de julho de 2000 . Regulamenta o art. 225, § 10, incisos I, II, III e VII da Constituição Federal, institui o Sistema Nacional de Unidades de Conservação da Natureza e dá outras providências. Brasília: MMA/SBF, 2000.

BRASIL. Terra Brasilis. Taxa de desmatamento na Amazônia. 2019. Disponível em: http://terrabrasilis.dpi.inpe.br/app/dashboard/defore station/biomes/legal amazon/rates. Acesso em: 07 dez 2019.

CABRAL, E. R.; GOMES, S. C. Gestão ambiental pública em municípios com forte correlação entre desmatamento e expansão da pecuária, da soja e da madeira. Ensaios FEE, v. 34, n. 1, p.167-194, 2013.

CÂMARA, G.; CARVALHO, M. S. Análise espacial de eventos. 2. ed. Brasília: Inpe, 2002. Disponível em:

www.dpi.inpe.br/gilberto/tutoriais/analise/cap1.pdf. Acesso em: 08 jul.2019.

CARPENTER, S. R.; BOOTH, E. G.; GILLOM, S.; KUCHARIK, C. J.; LOHEIDE, S.; MASE, A. S.; MOTEW, M.; QIU, J.; RISSMAN, A. R.; SIFERT, J.; SOYLU, E.; TURNER, M.; WARDROPPER, C. B. Plausible futures of a social-ecological system: Yahara watershed, Wisconsin, USA. Ecology and Society, v. 20, n. 2, p. 10, 2015.

CASTELO, T.B. Brazilian forestry legislation and to combat deforestation government policies in the Amazon. Revista Ambiente \& Sociedade, v. 18, n. 4, p. 215-234, 2015.

CASTRO, A. R. C.; WATRIN, O. S. Análise espacial de áreas com restrição legal de uso do solo em projeto de assentamento no sudeste paraense. Revista Geografia, Ensino \& Pesquisa, v. 17, n. 2, p. 157-166, 2013.

CHEN, G.; RYAN, P. P.; CARVALHO, L. M. T.; MORA, B. Spatiotemporal patterns of tropical deforestation and forest degradation in response to the operation of the Tucurui hydroelectric dam in the Amazon basin. Applied Geography, v. 63, p. 1-8, 2015.

CORTEZ, H. M.; SÁ, S.C.; PEREIRA JÚNIOR, A. Quantificação do desflorestamento no município de Canaã dos Carajás com o uso de geotecnologia em análise multitemporal. In: PEREIRA JÚNIOR, A.; JESUS, E. S.; RIBEIRO, J. M. F. As múltiplas visões do meio ambiente e os impactos ambientais. Porto Alegre: Simplíssimo, 2019. V. 2, cap. 5 , p. 02-32.

COSTA, E.; PIRES, G. Diagnóstico socioeconômico e ambiental da região de integração do Araguaia. Belém: FAPESPA, 2013. Disponível em: https://www.seplan.pa.gov.br/sites/default/files/PDF /ppa/ppa2016-2019/perfil regiao araguaia.pdf. Acesso em: 31 jul.2020

CRAVEIRO, I. C. P. Uso de geotecnologias na detecção do desmatamento na reserva extrativista Cazumbá-Iracema no estado do Acre. 2013. Monografia (Especialização) Universidade Federal do Paraná, Curitiba, 2013.

CRAVO, S. C.; JANZANTTI, P. H. F. O geoprocessamento como meio operacional e estratégico para defesa fronteiriça. Revista Brasileira de Estudos de Defesa, v. 5, n. 1, p. 167191, 2018.

CRUZ, F. M. Avaliação geoambiental e hidrológica da bacia do rio Itacaiunas, PA. 2010. Dissertação (Mestrado) - Centro de Geociências, Universidade Federal do Pará, Belém, 2010.

DELAZERI, L. M. Determinantes do desmatamento nos municípios do Arco Verde - Amazônia Legal: uma abordagem econométrica. EconomiaEnsaios, v. 30, n. 2, p. 11-34, 2016.

DOMINGUES, E. P.; CARVALHO, T. S.; MAGALHÃES, A. S. Cenário de referência e impactos de investimentos públicos e privados no estado do Pará. Urbis Amazônia, 2013. Disponível em:

http://www.dpi.inpe.br/urbisAmazonia/lib/exe/fetch. php?media=urbis:producoes:rel:anexo d egc ama zonia.pdf. Acesso em: 29 jul. 2010.

DUBREUIL, V.; FANTE, K. P.; PLACHON, O.; SANT'ANNA NETO, J. L. Les types de climats annuels au Brésil: une application du classement de Köppen de 1961 a 2015. Revista Confins FrancoBrésilienne de Géographie, n. 37, p. 01-27, 2018.

FAPESPA. FUNDAÇÃO AMAZÔNICA DE AMPARO A ESTUDOS E A PESQUISAS. Boletim Agropecuário do Pará 2017. 2017, p. 10-11. Disponível em: http://www.fape spa.pa.gov.br/upload/Arquivo/anexo/1383.pdf?id=1 533567716. Acesso em: 16 set. 2019.

FARIAS, M. H. C. S.; BELTRÃO, N. E. S.; SANTOS, C. A.; CORDEIRO, Y. E. Impacto dos assentamentos rurais no desmatamento da 
Amazônia. Mercator, v. 17, p. 01-20, 2018. Disponível em: https://www.scielo.br/pdf/mercator/v17/1984-2201mercator-17-e17009.pdf. Acesso em: 03 ago. 2020.

FEARNSIDE, P. M. Desmatamento na Amazônia: dinâmica, impactos e controle. Acta Amazonica, v. 36 , n. 3, p. 3395-400, 2006.

FERREIRA, A. L. S.; PASA, M. C. O uso de geotecnologia aplicada ao monitoramento de desmatamento do Pantanal Mato-grossense. Advances in Forestry Science, v. 2, n. 2, p. 41-47, 2015.

FIGUEROA, S. N.; NOBRE, C. A. Precipitations distribution over Central and Western Tropical South America. Climanálise - Boletim de Monitoramento e Análise Climática, v. 5, n. 6, p. 36-48, 1990.

FISCH, C. G.; MARENGO, J. A.; NOBRE, C. A. Uma revisão geral sobre o clima da Amazônia. Acta Amazônica, v. 28, n. 1, p. 101-126, 1998.

FREIRE JÚNIOR, A. B.; INÁCIO, H. D. A importância do Cadastro Ambiental Rural. Âmbito Jurídico, v, 01, p. 01, 2017.

IBGE. INSTITUTO BRASILEIRO DE GEOGRAFIA E ESTATISTICA. CENSO 2010. Disponível em: https://censo2010.ibge.gov.br/. Acesso em: 01 ago. 2020.

IMAZON. INSTITUTO DO HOMEM E DO MEIO AMBIENTE DA AMAZÔNIA. Boletim do desmatamento da Amazônia Legal (janeiro 2019) SAD. 2019. Disponível em: <https://imazon.org.br/publicacoes/boletim-dodesmatamento-da-amazonia-legal-janeiro-201 9 $\mathrm{sad} />$. Acesso em: 06 mar. 2020.

INPE. INSTITUTO NACIONAL DE PESQUISAS ESPACIAIS. Perguntas Frequentes. Disponível em: <http://www.inpe.br/queimadas/portal>. Acesso em: 13 jul. 2019.

PRODES. Divulgação da taxa estimada de desmatamento da Amazônia Legal para o Período 2013-2014. 2014. Disponível em: <socioambiental.org/sites/blog.socioambiental.org/f iles/nsa/arquivos/64298557-25b3-413e-a.pdf>. Acesso em: 29 jul.2020.

ITO, M. H; FONSECA FILHO, H.; CONTI, L. A. Uso de software livre QGIS (Quantum GIS) para ensino de geoprocessamento em nível superior. Revista Cartográfica, p. 127-148, 2017. Disponível em:
http://comisiones.ipgh.org/CARTOGRAFIA/rca/RC A94 Digital.pdf. Acesso em: 30 jul. 2020.

LOBATO, M. M. A dinâmica na fronteira paraense e os territórios do capital: pecuária, extração madeireira e mineração. Revista Formação (online), v. 26, n. 47, p. 89-119. 2019.

LOPES, R. R.; SANTOS, M. M.; CRUZ, T. M. Mineração e conflitos pela posse da terra em Canaã dos Carajás: O caso do acampamento Planalto Serra Dourada. Revista de Extensão e Estudos Rurais, v. 7, n. 2, p.117-140, 2018.

LOUZADA, C. A. Impacto dos eventos ENOS (El Niño e La Niña) na agricultura familiar no estado do Amazonas. Formação, v. 26, n. 49, p. 143-162, 2019.

LUZ, E. S. Mercado de madeira e qualidade de toras de espécies tropicais no estado do Pará: subsídios para o manejo florestal sustentável. 2018. Monografia. (Graduação) - Universidade Federal do Paraná, Curitiba, 2018.

MANESCHY, C. E. A.; SOUZA, M I. L. P.; PAES, J. G. C. Região de Integração de Carajás. Perfil socioeconômico e ambiental. Belém: FAPESPA, 2019. Disponível em: http://www.age.pa.gov.br/sites/default/files/1 ri carajas.pdf. Acesso em: 30 jul. 2020

MARCONI, M. A.; LAKATOS, E. M. Técnica de pesquisa. 8 ed. São Paulo: Atlas, 2017.

MARTINS, E. A. C.; ARAÚJO, R. P. Z.; DE PAULA, P. L. Geographic visualization as a planning support tool to improve public participation in new urban development decision making processes: geodesigning potential housing areas at the Iron Quadrangle in Minas Gerais, Brazil. Revista Brasileira de Cartografia, v. 69, n. 8, p. 1476-1492, 2017.

MATOS, F. L. L. C. C. Análise das taxas anuais de desmatamento na Amazônia Legal a partir da relação entre autos de infração e área desmatada no período entre 2000 e 2014. 90 p. 2016. Dissertação (Mestrado) - Universidade de Brasília, Brasília, 2016.

MELLO, A. H.; GAMA, M. F. F.; OLIVEIRA, G. F.; SILVA, J. C. Diagnóstico da degradação ambiental em áreas de extração de argila em Marabá - PA. Agroecossistemas, v. 9, n. 1, p. 45-61, 2017.

MELLO, N. G. R.; ARTAXO, P. Evolução do Plano de Ação para Prevenção e Controle do 
Desmatamento na Amazônia Legal. Revista do Instituto de Estudos Brasileiros, n. 66, p. 108129, 2017.

MENGATTO JÚNIOR, E. A.; OLIVEIRA, R. C.; SILVA, J, S. V. O município de Marabá, PA frente ao ZEE na Amazônia Legal: avaliação das taxas de desmatamento. In: SIMPÓSIO BRASILEIRO DE GEOGRAFIA FÍSIC APLICADA, 17., 2017, Campinas. Anais eletrônicos ... Campinas-SP: Unicamp, 2017. Disponível em: https://ocs.ige.unicamp.br/ojs/sbgfa/article/view/22 06. Acesso em: 29 jul.2020.

MESSIAS, C. G.; FERREIRA, M. M. Estudo geomorfológico de bacias hidrográficas do reservatório do funil, Alto Rio Grande (MG), por meio de imagens estereoscópicas ALOS/PRISM. Revista do Departamento de Geografia, v. 28, p. 237-262, 2014.

MESQUITA, E. A.; CRUZ, M.L. Geoprocessamento aplicado ao mapeamento das formas de uso da terra na Área de Preservação Permanente (APP) da Lagoa do Uruaú - Beberibe/Ce. Revista Geonorte, v. 2, n. 4, p. 1509-1518, 2012.

MITSCHEIN, T. A.; CHAVES, J. F.; PAIXÃO, F. J. M.; IMBIRIBA, B. C. O.; MIRANDA, P. S. Riquezas minerais e polarização socioeconômica nos municípios do Sudeste Paraense: o caso de Água Azul do Norte. Belém: IMEC/UFPA, 2016.

MMA. MINISTÉRIO DO MEIO AMBIENTE. Sistema Nacional de Unidades de Conservação da Natureza; Plano Estratégico de Áreas Protegidas. Brasília: MMA/SBF, 2011.

Saiba o que é desmatamento e quem o monitora no Brasil. Brasília: MMA. 2018. Disponível em: <http://www.brasil.gov.br/ noticias/meio-ambiente/2012/04/saiba-o-que-edesmatamento-e-quem-o-monitora-nobrasil>.

Acesso em: 04 fev. 2019.

MMA/ICMBio. MINISTÉRIO DO MEIO AMBIENTE/INSTITUTO CHICO MENDES DE CONSERVAÇÃO DA BIODIVERSIDADE. Portaria n. 418, de 23 de agosto de 2019. Aprova o Plano de Conservação Estratégico para o Território de Carajás. Diário Oficial [da] União, n.166, de 28 ago. 2019, Seção1, p. 414.

MOURA, R.; SANTOS, D.; VERÍSSIMO, A.; NUNES, S.; BRITO, B.; BARRETO, P.; MARTINS, H.; CELENTANO, D. Desmatamento zero no Pará: desafios e oportunidades. Belem: IMAZON, 2017.
MOUTINHO, P.; GUERRA, R.; RAMOS, C. A. Achieving zero deforestation in the Brazilian Amazon: What is missing. Elementa: Science of the Anthropocene, v. 4, p. 01-11, 2016.

NEVES, P. A. P. F. G.; SILVA, L. M.; PONTES, A. N.; DE PAULA, M. T. Correlação entre pecuária e desmatamento em municípios da mesorregião sudeste do estado do Pará. Ambiência, v. 10, n. 3, p. $795-806,2014$

NOBRE, C. A.; SAMPAIO, G.; BORMA, L. S.; CATILLA-RUBIM, J. C.; SOLVA, J. S.; CARDOSO, $M$. Land-use and climate change risks in the Amazon and the need of a novel sustainable development paradigm. PNAS, v. 113, n. 39, p. 10759-10768, 2016.

OTI, D.; EWUSI, A. Hydrometeorological trends of Tocantins and Itacaiúnas Rivers in Brazil. In: UMA BIENNIAL INTERNATIONAL MINING AND MINERAL CONFERENCE, 4., 2016, Ghana. Anais... Takoradi: Natural Resource Governance Institute, 2016. p. 114-126.

PALHETA, J. M.; SILVA, C. N.; OLIVEIRA NETO, A.; NASCIMENTO, F. R. Conflicts over the use of territory in mineral Amazon. Mercator, Fortaleza, v. 16, 2017.

PANTOJA, M. A. L.; NASCIMENTO, D. N. O.; AGUIAR, E. S.; BEZERRA, K. C. A.; DIAS, Y. A.; PEREIRA, B. W. F. Uso de SIGs para análise de informações do Cadastro Ambiental Rural no Município de Igarapé-Açu. SIMPÓSIO BRASILEIRO DE SENSORIAMENTO REMOTO, 17., 2015, João Pessoa. Anais eletrônicos... João Pessoa-PB: INPE, 2015. Disponível em: http://urlib.net/rep/sid.inpe.br/marte2/2015/05.31.21 .54/capa.htm. Acesso em: 20 jul. 2020.

PARÁ. Lei Ordinária n. $\mathbf{5}$ 5.983, de 25 de julho de 1996. Cria a Área de Proteção Ambiental de São Geraldo do Araguaia, no município de São Geraldo do Araguaia e dá outras providências. Pará, Secretaria de Estado de Meio Ambiente e Sustentabilidade. 1996. Disponível em: https://www.semas.pa.gov.br/legislacao/files/pdf/41 3.pdf. Acesso em 03 ago. 2020.

PASSOS, P.H. S.; SILVA, J. U. B. Aspectos socioeconômicos e produtivos do município de Sapucaia - Pará, Amazônia, Brasil. Observatório da La Economia Latino Americana, 2016. Disponível

em: http://www.eumed.net/cursecon/ecolat/br/16/s apucaia.html. Acesso em: 01 ago.2020. 
PAULO, E. M. S.; SOUZA, M. J. N. Sistemas de informações geográficas na análise da vulnerabilidade ambiental da Bacia do Rio CearáCE. Revista Brasileira de Cartografia, n. 63/04, p. 545-554, 2011.

PEREIRA JÚNIOR, A.; DOS SANTOS, A. M. Análise multitemporal da supressão vegetal no município de Xinguara - PA. Revista Eletrônica de Gestão e Tecnologias Ambientais, v. 4, n. 2, p. 260-277, 2016

RAIOL, J. A. (Coord.). Perspectivas para o meio ambiente urbano. GEO Marabá. Brasília: PNUMA/ONU-

HABITAT/IBAM/ISER/MMA/Ministério das Cidades, 2009.

ROLNIK, R.; KLINK, J. Crescimento econômico e desenvolvimento urbano: Por que nossas cidades continuam tão precárias? Novos Estudos, n. 89, p. 89-109, 2011.

ROSA, L. A. S. A bacia hidrográfica como unidade territorial de gestão ambiental no Programa de Revitalização do rio São Francisco. 2011. Monografia (Especialização) - Centro de Desenvolvimento Sustentável, Universidade de Brasília, Brasília, 2011.

RUBIRA, F. G. Definição e diferenciação dos conceitos de áreas verdes/espaços livres e degradação ambiental/impacto ambiental. Caderno de Geografia, v. 26, n. 45, p. 134-150, 2016.

SANTOS, T. N. O.; SOUZA, E. L.; ARAÚJO, M. F. A reinvenção do agronegócio no sudeste paraense: uma análise do avanço da soja e sua relação com a sustentabilidade. Revista Agropampa, v. 2, n. 2, p. 177-190, 2018.

SANTOS, T. O.; ANDRADE FILHO, V. S.; ROCHA, V. M.; MENEZES, J. S. Os impactos do desmatamento e queimadas de origem antrópica sobre o clima da Amazônia brasileira: um estudo de revisão. Rev. Geogr. Acadêmica, v. 11, n. 2, p. 157-181, 2017.

SEDAP. Secretaria de Estado de Desenvolvimento Agropecuário e de pesca. Pará. 2019. Disponível em: http://www.sedap.pa.gov.br/regi\%C3\%A3o-deintegra\%C3\%A7\%C3\%A3o-do-caraj\%C3\%A1s.

Acesso em: 31 jul. 2020

SEMAS. Secretaria de Meio Ambiente e Sustentabilidade. Rima. Projeto Pedra Branca. $2018 . \quad$ Disponível em: https://www.semas.pa.gov.br/wp-
content/uploads/2018/02/RIMA PEDRA BRANCA. pdf. Acesso em: 01 ago. 2020.

SEPLAN. Secretaria de Planejamento. Anexo X. Regiões de Integração e Municípios do Estado do Pará. 2016. Disponível em: http://www.seplan.pa.gov.br/sites/default/files/PDF/l oa/loa2016/13.anexo x -

regioes de integracao e municipios do estado do para.pdf. Acesso em: 31 jul.2020.

SERRÃO, E. A. O. Aplicação do modelo Swat na simulação hidrológica da bacia hidrográfica do Rio Itacaiúnas-PA. 2018. Dissertação (Mestrado) Universidade Federal de Campina Grande, Campina Grande-PB, 2018.

SILVA JÚNIOR, R. O. Resposta hidrológica devido às mudanças no uso do solo e cobertura vegetal na bacia hidrográfica do rio Itacaiúnas (BHRI). 2017. Dissertação (Mestrado) Universidade Federal do Pará, Belém, 2017.

SILVA, J. X. Geoprocessamento no apoio à decisão. Revista Continentes, v. 5, n. 9, p. 105115, 2016.

SILVA, M. R.; COSTA NETO, J. F. Análise multitemporal da cobertura florestal do município de Eldorado dos Carajás, PA. In: SIMPÓSIO BRASILEIRO DE SENSORIAMENTO REMOTO, 16., 2013, Foz do lguaçu. Anais eletrônicos ... Foz do Iguaçu-PR: Inpe, 2013. Disponível em: http://marte2.sid.inpe.br/col/dpi.inpe.br/marte2/201 3/05.28.22.25/doc/@sumario.htm. Acesso em: 30 jul. 2020

SIRGAS. Sistema de Referência Geocêntrica para as Américas. 2000. Disponível em: http://www.sirgas.org/pt/sirgasrealizations/sirgas2000/. Acesso em: 04 ago.2020.

SOUZA, I. R.; SOARES, L. T.; SOARES, P. V.; TEIXEIRA, D. L. S.; MORAES, T. S.; GRILO, L. M. Análise da dinâmica do desmatamento da Amazônia legal com ênfase no estado do Pará. 2018. In: ENCONTRO ACADÊMICO DA ENGENHARIA AMBIENTAL DA EEL-USP, 2., 2018, São Paulo. Anais... Lorena-SP: Escola de Engenharia de Lorena (EEL), 2018.

SOUZA, P. P. L. R. Desenvolvimento rural no contexto amazônico: uma análise multidimensional do Estado do Pará. 2014. Dissertação (Mestrado) - Pontífice Universidade Católica do Rio Grande do Sul, Porto Alegre, 2014. 
SOUZA-FILHO, P. W. M.; NASCIMENTO, W. R.; MENDONÇA, B. R. V.; SILVA JÚNIOR, R. O.; GUIMARÃES, J. T. F.; DALL'AGNOL, R.; SIQUEIRA, J. O. Changes in the land cover and land use of the Itacaiúnas river watershed, arc of deforestation, Carajás, Southeastern Amazon. In: INTERNATIONAL SYMPOSIUM ON REMOTE SENSING OF ENVIRONMENT, 36., 2015, Berlin. Anais eletrônicos... Berlin: German Aerospace Center (DLR), 2015. Disponível em: https://ec.europa.eu/jrc/en/event/conference/36thisrse\#: :text=The\%2036th\%20International\%20Sy mposium\%20on, \%2C\%202015\%20in\%20Berlin\%2 C\%20Germany. Acesso em: 30 jul. 2020.

SOUZA-FILHO, P. W. M.; SOUZA, E. B.; SILVA JÚNIOR, R. O.; NASCIMENTO JÚNIOR, W. R.; MENDONÇA, B. R. V.; GUIMARÃESS, T. F.; DALL'GNOL, R.; SIQUEIRA, J. O. Four decades of land-cover, land-use and hydro climatology changes in the Itacaiúnas River watershed, southeastern Amazon. Journal of Environmental Management, v. 167, p. $175-184,2016$.

TORRES, F.T.P.; ROQUE, M. P. B.; LIMA, G. S.; MARTINS, S. V.; FARIA, A. L. L. Mapeamento do risco de incêndios florestais utilizando técnica de geoprocessamento. Floresta e Ambiente, v. 24, p. 1-10, 2017.

VIANA, P. L; GIL, A. S. B. Flora das cangas da Serra dos Carajás, Pará, Brasil: Cannabaceae. Rodriguésia, v. 69, n. 1, p. 049-051, 2018.

VIEIRA, A. A. N.; CLEMENTE, A.; DIAS, G. A.; FRANCA FILHO, M. T. Metodologia científica no Brasil: ensino e interdisciplinaridade. Educação \& Realidade, v. 42, n. 1, p. 237-260, 2017.
VIEIRA, M. H. P.; PEREIRA, E. F.; VIEIRA, J.; LOUZADA, R. O.; SILVA, M. C. A.; FERREIRA, L. M. Mapas de Kernel como alternativa ao monitoramento ambiental: análise das indústrias que realizam emissões nos municípios do estado de Mato Grosso do Sul, nos anos 2008 a 2018. In: SIMPÓSIO DE GEOTECNOLOGIAS NO PANTANAL, 7., 2018, Jardim. Anais eletrônicos... Jardim-MS: Embrapa, 2018. Disponível em: https://www.geopantanal.cnptia.embrapa.br/AnaisGeopantanal/Inicio.html. Acesso em: 17 nov. 2020.

VILLELA, R.; BUENO, R. S. A Expansão do desmatamento no Estado do Pará: população, dinâmicas territoriais e escalas de análise. In: CONGRESO DE LA ASOCIACIÓN LATINO AMERICANA DE POBLACIÓN E ENCONTRO NACIONAL DE ESTUDOS POPULACIONAIS, 7., 2016, Foz do Iguaçu. Anais eletrônicos... Foz do Iguaçu-PR: Associação Brasileira de Engenharia de Produção, 2016. Disponível em: http://www.abep.org.br/ abeporgb/publicacoes/ind ex.php/anais/issue/view/41. Acesso em: 20 jul. 2020.

WITHEY, K.; BERENGER, E.; PALMEIRA, A. F.; ESPIRITO-SANTO, F.D. B.; LENNOX, G. D.; SILVA, C. V.; ARAGÃO, L. E. O. C.; FERREIRA, J.; FRANÇA, F.; MALHI, Y.; ROPSSI, L. C. R.; BARLOW, J. Quantifying immediate carbon emissions from El Niño-mediated wildfires in humid tropical forests. Philosophycal Transactions of the Royal Society B., 373: 20170312, 2018.

WHITE, B. L. A.; WHITE, L. A. S. Queimadas controladas e incêndios florestais no estado de Sergipe, Brasil, entre 1995 e 2015. Floresta, v. 46, n. 4, p. 561-570, 2016.ZAIDAN, R. T. Geoprocessamento, conceitos e definições. Revista de Geografia, v. 7, n. 2, p. 194-201, 2011. 